\title{
Pengaruh Pengembangan Karir dan Motivasi Kerja Terhadap Kepuasan Kerja Karyawan di Pt. Sumber Alfaria Trijaya Kota Jambi
}

\author{
${ }^{1}$ Kasful Anwar US, ${ }^{2}$ Doni Kurniawan \\ ${ }^{1-2}$ Fakultas Ekonomi dan Bisnis Islam, Universitas Islam Negeri Sulthan Saifuddin Jambi
}

\author{
Article history \\ Received:04-Mei- 2021 \\ Revised: 12-Juni-2021 \\ Accepted:08-July-2021 \\ *Corresponding Author: \\ Kasful Anwar, \\ Doni Kurniawan \\ Fakultas Ekonomi dan \\ Bisnis Islam, \\ Universitas Islam Negeri \\ Sulthan Saifuddin Jambi \\ Email:
}

\begin{abstract}
Abstrak: Penelitian ini bertujuan untuk menjelaskan apakah variabel pengembangan karir dan motivasi kerja berpengaruh secara signifikan terhadap kepuasan kerja karyawan pada PT. Sumber Alfaria Trijaya serta mengetahui variabel manakah yang lebih dominan di antara keduanya. Dari hasil data yang di analisis dengan menggunakan metode kaulitatif dan metode kuantitatif, didapati hasil yang menunjukkan bahwa secara bersama sama atau simultan, kedua faktor yang di teliti ini memiliki pengaruh yang positif terhadap varibel bebasnya yakni kepuasan kerja karyawan dengan hasil $Y=9,495+0,455 X 1+0,202 X 2+e$. Kemudian bila di tinjau dari nilai hasil koefisien determinasi di dapati hasil bahwa besarnya kontribusi dua variabel ini terhadap kepuasan kinerja mencapai 59,9\% dan sisanya di pengaruhi oleh faktor lain, yang dengan demikian disimpulkan bahwa variabel yang di teliti ini berpengaruh pada kepuasan kerja karyawan
\end{abstract}

Kata Kunci : Pengembangan Karir, Motivasi Kerja, Kepuasan Kerja Karyawan

\section{PENDAHULUAN}

Sumber Daya Manusia (SDM) merupakan sebuah pondasi yang memiliki keterlibatan langsung dalam menjalankan kegiatan organisasi dalam mencapai tujuan yang diharapkan dan ditetapkan. Organisasi yang baik memiliki citra yang baik dan positif di mata Masyarakat dengan tidak mengabaikan aspek pengembangan kualitas sumber daya manusianya. Oleh beba itu pernana sumber daya manusia didalam organisasi sangat di perlukan. Manusa yang hendak melakukan pengembangan karir tentunya harus memiliki motivasi kerja untuk mencapai kepuasan kerja karyawan yang maksimal.

Pengembangan karir menurut Siagian(2007) ialah peribahan pribadi yang dilakukan seseorang untuk mecapai suatu rencana karir, sedangkan menurut Stone dalam Gomes(2007) ia menyatakan bahw pengembangan karir menujukkan proses dan kegiatan seorang oegawai untuk jabatan dalam organisasi yang akan datang. Pengembangan karir di perusahan disagka baik berdasrkan pendidian formal, pengalaman kerja, prestasi kerja, keterampilan kerja, produktivitas kerja, penaikan kabatan, peningkatan karir, pelatihan karyawan, jenjang karir, dan perencaanaan kerja, motivasi kerja yang baik akan di berikan oleh perusahaan melalui pemberian agji, tunjangan perumahan, tunjangan pensiun, hubungan rekan kerjam hubungan dengan atasam pemberian bonus dan pengahrgaan, promosi jabatan, kebebasan beroendapat serta penilaian serta kritik. Pengembangan karir berpangaruh secara signifikan terhap motivasi kerja di PT. Sumber Alfaria Trijaya (Alfamart) Kota Jambi.

Motivasi kerja merupakan sebuah daya pendorong atau penggerak yang dimiliki setiap prang untuk melakukan suatu kegiatan agar ia mau berbuat, melakukan sesuatu, bekerjam serta beraktifitas untuk menggunakan segenap kemampuan dan potensi yang di milikinya untuk mencapai tujuan yang di kehendakai sebagiamana diteteapkan sebelumnya. Untuk mewujdukan motivasi kerja yang tinggi memrlukan pehratian khsusu 
kepada karyawan guna mengahsilkan laba yang fantastis untuk perisahaan. Seperti yang di kemukan oleh Stephen P. Robbie (2011), motivasi merupakan sbeuah lerelaan untuk berusaha seoptimal mungkin dalam mencapai tujuan organisasi yangd I penagurhi oleh kemampuan usah auntuk memuaskan beberapa kebutuah individu. Par akaryawan dalam termotivasi apabila penetapan tujuan perusahaan di dasrkan atas kepentingan dak kebutuhan karyawan. Husman(2002) mengemukakan beberapa factor yang motivasi kerja yang dipengaurhi oleh keuasan kerja yakni gaji yang baik, pekrejana yang aman, rekan kerja yang kompak, pengehargaan terhdap pekejraan danpekerjana yang berarti. Motivasi merupakan factor pendorong seseorang menimbulkan smeangat kerja yang tinggi juga.

Kepuasan kerja mencakup berbagai hal seperti kondisi dan kecenderungan perilaku seseorang, kepuasna kepuasan ini tidak tampak seerta nyata, tetapi dapat di wujudkan dalam suatu hasil pekerjaan. Salah satu maslaah yang sangat pendint agar mendoorng karyawan untuk bekerja dengan lebih produktif. Hasibuan (2007) beroendaoat bahwa kepuasan kerja merupakan sikap emosional yang menyenangkan dan mencintai pekerakaannya. Sikap ini di cerminkan oleh moral kerja, kesidisplinan, prestasi kerja. Kepuasn kerjad dinikmati dalam pekerjaan, luar pekerjan dan kombinasi dari dalam dan luar pekerjaan.

\section{Landasan Teori}

\section{a. Pengembangan Karir}

Pengembangan karir pada dasarnya ditunjukkan untuk pembangunan organisasi atau perusahaan guna memenuhi tantangan bisnis di masa yang akan datang. Sumber daya manusia yang tidak kompetetif, organisasi akan mengalami kemunduran dan pada akhirnya akan tersingkirkan karena ektidak mampuannya menghadapi pesaning, kondisi seperti itu menurut organisasi harus terencana dalam pengembangan karyawan berkelanjutan. Sebelumnya, definsii pekerjaan itu sendiri perlu di pahami terlebih dahulu. Pengembangan karir merupakan salah satu kondiri terkait peningkatan status seseorang dalam sbeuah organisasi dan jalur karir yan telah di tetapkan (Kumalasari, 2015). Sedangkan Hasibuan (2016) menjealskan bahwa pengembangan karir meruapkan perpindahan yang memperbedar tanggung jawab karywan ka jabatan yang lebih tinggi dalam sebuah organisasi sehingga kewajiban, hak dan status menjadi lebih besar.

b. Motivasi Kerja

Tidak sedikit karyawan dalam organisasi atau perusahahaan yang merupakan masyrakat mandiri dengan karakteristik nya masing masing. Suasana psikologis yang terbilang bagian dari hal internal tiap individu dalam organisasi akan mejadi lingkungan kerja yang memiliki pengaruh besar terhap pelaksanaan pekerjaannya. Motivasi kerja yang mempunyai pengaruh besar terhadap pelaksanaan pekerjaannya. Motivasi karyawan akan sangat di pengaruhi oleh motivasi kerjanya. Pentingnya motivasi ini akan menimbulkan, membimbing dan mendukung perilaku manusia sehingga ada kemauan untuk berkeja keras demi mendapakan hasil yang terbaik. Pparashakto (2020) mengemukakan bahwa motivasi kerja dapat merangsang timbulnya dan meningkatnya semangat kerja, motivasi kerja di artikan sebagai kondisi yang mempengaruhi, ,membimbing, dan memelihara perilaku terkait pekerjaan, menurut Mc Cornick (2015) motivasi kerja seorang karyawan dapat tumbuh sendiri atau perlu di motivasi dan di dorong oleh pimpinan, itulah sebabnya seseorang menunjukkan perbeadaan menangani siatuasi tertent di bandingkan dengan orang lain yang menghadapi.

c. Kepuasan Kerja

Kepuasan kerja menurut Sunyoto (2012) merupakan cerminan perasaan seseorang terhadap kerjaannya, hal ini di tampakkan melalui sikap positif yang di berikan oleh karyawan terhadap pekerjannya dan segala sesuatu yang di hadapi di lingkungan 
kerjanya. Kepuasan kerja pada dasarnya merupakan hal yang sama. Memurut ssitem nilai yang berlaku pada dirinya, setiap orang akan memiliki tingkat kepuasan yang berbeda beda. Kepuasn kerja merupakan sikap profit yang melibatkan penyesuaian kesehatan karyawan terhadap kondiri dan kondoro kerja, termasuk gaki, sosial, fisik dan psikologis. Kepuasan kerja di terima secara umum ada tiga dimensi, yakni : (1) kepuasan kerja merupakan respon emosional terhadap situasi kerja, sehingga kepuasan kerja dapat di lihat diprediksi. (2) kepuasan kerja biasanya bergantung pada sebarapa baik hasil yang di capai memenuhi syarat atau melebihi harapan. (3) kepuasan kerja mewakili beberapa sikap terkait. Kepuasan kerja sangat berperan dalam membentuk kedisiplinan, komitmen dan kinerja karyawan yang kemudian berpengaruh tahadap usaha mencapai tujuan perusahaan, (Mathis, 2011)

\section{Hipotesis}

Berdasarakan landaran teori diatas dapat di simpulkan bahwa kepuasan kerja karyawan biasanya dipengaruhi oleh berbagai faktor, dan penelitian ini menfouskannya terhadap dua faktor variabel yang mempengaruhi kepuasan kerja tersebut, yakni : Pengembangan karir dan motivasi kerja. Berdasarkan uraian tersebut maka dapat di rumuskan kerangka pemikran yang dapat dilihat pada gambar berikut :

\section{Gambar 1 Design Penelitian}

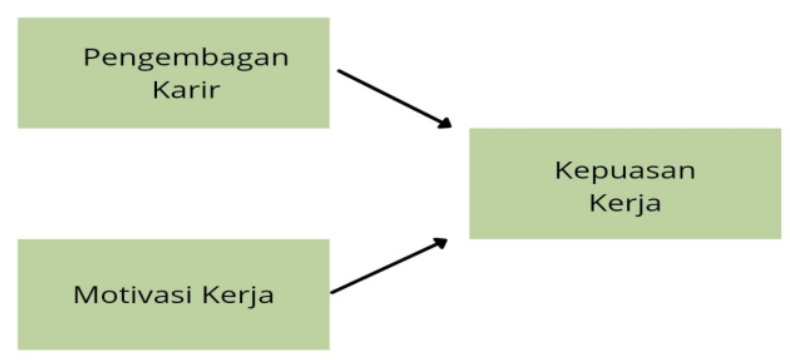

Dan hipotesis yang akan di kaji dalam penelitian ini ialah :

H1 : Diduga pengembangan karir dan motivasi kerja tidak berpengaruh secara signifikan terhadap kepuasan kerja pada PT. Sumber Alfaria Trijaya (Alfamart) Kota Jambi

H2 : Diduga pengembangan karir dan motivasi kerja berpengaruh secara signifikan terhadap tingkat kepuasan kerja pada PT. Sumber Alfaria Trijaya (Alfamart) Kota Jambi

\section{METODE PENELITIAN}

Penelitian ini menggunakan penelitian kuantitataid. Obyek penelitian dalam penelitian ini adalah PT. Sumber Alfaria Trijaya (Alfamart) Kota Jambi, dengan populasi seluruh karyawan yang bekerja di PT. Sumber Alfaria Trijaya, dan sampel karyawan sebanyak 21 karyawan saja yang di pilih secara acak. Metode pengumpulan data yang di gunakan dalam penelitian ini ialah survei kuisioner

\section{Metode Analisis Data}


Penelitian ini di lakukan untuk mengetahui pengaruh pengembangan karir dan motivasi kerja terhadap kepuasan kerja karyawan, maka analisis data ang di gunakan ialah :

a. Metode Kualitatif

Analisis kualitatis meurpakan sebuah analisis diman asat ayang diperoleh mengenai obyek penelitian yang merupakan data kualitatif dianalisis berdasarkan perbandingan antar teori dan literatur dengan kenyataan yang di peroleh penulis selama penelitian

b. Metode kuantitatif

1. Uji Validitas dan Reliabilitas

2. Analisis Regresi Linier Berganda

Termasuk : Koefisien Determinasi, Anova (uji F), Uji T, Persamaan Umum Regresi Linier Berganda

\section{HASIL DAN PEMAHASAN}

1. Uji Normalitas

Tabel 1 Uji Normalitas

\begin{tabular}{|c|c|c|}
\hline \multicolumn{3}{|c|}{ One-Sample Kolmogorov-Smirnov Test } \\
\hline & & $\begin{array}{c}\text { Unstandardized } \\
\text { Residual }\end{array}$ \\
\hline $\mathrm{N}$ & & 21 \\
\hline \multirow[t]{2}{*}{ Normal Parameters ${ }^{\mathrm{a}, \mathrm{b}}$} & Mean & .0000000 \\
\hline & Std. Deviation & 2.43434175 \\
\hline \multirow{3}{*}{$\begin{array}{l}\text { Most Extreme } \\
\text { Differences }\end{array}$} & Absolute & .138 \\
\hline & Positive & .138 \\
\hline & Negative & -.103 \\
\hline \multicolumn{2}{|l|}{ Kolmogorov-Smirnov Z } & .631 \\
\hline \multicolumn{2}{|l|}{ Asymp. Sig. (2-tailed) } & .820 \\
\hline \multicolumn{3}{|c|}{ a. Test distribution is Normal. } \\
\hline \multicolumn{2}{|l|}{ b. Calculated from data. } & \\
\hline
\end{tabular}

Pengujian ini di lakukan untuk menguji apakah dalam model regresi cariavel dependen dan indepen memiliki distribusi normal data yang baik dan layak digunakan dalam penelitian ini adalah daya yang memiliki distribusi normal. Jika nikai Asymp.Sig (2tailed) lebih besar dari 0,1 maka dapat di simpulkan bahawa data berdistribusi secara normal.

\section{Uji Multikolonieritas}

Tabel 2 Uji Multikolonieritas

\begin{tabular}{llll}
\hline & & Coefficients $^{\mathbf{a}}$ & \\
\hline & & & \\
\cline { 3 - 4 } & & Collinearity Statistics \\
\cline { 3 - 4 } Model & & Tolerance & VIF \\
\hline 1 & (Constant) & & \\
& & & \\
\hline
\end{tabular}




\begin{tabular}{|c|c|c|}
\hline Pengembangan Karir (X1) & .533 & 1.876 \\
\hline Motivasi Kerja (X2) & .533 & 1.876 \\
\hline a. Dependent Variable: Perilaku Etis & $\ln (Y)$ & \\
\hline
\end{tabular}

Hasil uji multikolonoeritas dari masing masing variabel independent menunjukkan hasil nilai CIF tidak lebih dari 10, yang dengan begitu bial di tinjau dari nilai Tolerance memiliki nilai yang tidak kurang dari 0,1. Dapat di pastikan bahwamasing masing variabel independent terbebada dari multikolonieritas dalam model regresi.

\section{Analisis Regresi Linier Berganda}

\begin{tabular}{|c|c|c|c|c|}
\hline \multicolumn{5}{|c|}{ Coefficients $^{\mathrm{a}}$} \\
\hline & & \multicolumn{2}{|c|}{ Unstandardized Coefficients } & \multirow{2}{*}{$\begin{array}{c}\text { Standardized Coefficients } \\
\text { Beta } \\
\end{array}$} \\
\hline \multicolumn{2}{|c|}{ Model } & $\mathrm{B}$ & Std. Error & \\
\hline 1 & (Constant) & 9.495 & 4.753 & \\
\hline & Pengembangan Karir (X1) & .455 & .175 & .531 \\
\hline & Motivasi Kerja (X2) & .202 & .134 & .307 \\
\hline
\end{tabular}

Berdasarkan hasil analisis regresi linier berganda maka model persamaan antara variabel-variabel bebas terhadap variabel terikat adalah sebagai berikut:

$$
Y=9,495+0,455 X 1+0,202 X 2+e
$$

\section{Uji T}

\begin{tabular}{|c|c|c|c|c|c|c|}
\hline \multicolumn{7}{|c|}{ Coefficients $^{\mathbf{a}}$} \\
\hline & & Unstandar & Coefficients & Standardized Coefficients & \multirow{3}{*}{$\frac{\mathrm{t}}{1.997}$} & \multirow{3}{*}{$\begin{array}{c}\text { Sig. } \\
.061\end{array}$} \\
\hline \multicolumn{2}{|c|}{ Model } & $\mathrm{B}$ & Std. Error & Beta & & \\
\hline 1 & (Constant) & 9.495 & 4.753 & & & \\
\hline & Pengembangan Karir (X1) & .455 & .175 & .531 & 2.598 & .018 \\
\hline & Motivasi Kerja (X2) & .202 & .134 & .307 & 1.505 & .150 \\
\hline
\end{tabular}

a. Dependent Variable: Kepuasan Kerja (Y)

Cara pengambilan keputusan dapat dilakukan dengan membandingkan nilai t hitung dengan $\mathrm{t}$ tabel pada taraf signifikansi dalam penelitian yaitu 0,05 .. Jika nila $t$ hitung $<\mathrm{t}$ tabel maka hal ini berarti pengaruh antara variabel bebas terhadap variabel terikat tidak signifikan secara statistik. Namun jika nilai $t$ hitung $>\mathrm{t}$ tabel maka hal ini berarti pengaruh antara variabel bebas terhadap variabel terikat signifikan secara statistik. Nilai t tabel untuk derajat bebas 21-3=18 dan taraf signifikansi 0,05 adalah 2,1199.

\section{Uji F}

Tabel 5 Uji F

\begin{tabular}{lrrrrrr}
\hline \multicolumn{7}{c}{ ANOVA $^{\mathbf{b}}$} \\
\hline \multicolumn{2}{l}{ Model } & Sum of Squares & Df & Mean Square & F & Sig. \\
\hline \multirow{2}{*}{1} & Regression & 177.289 & 2 & 88.645 & 13.463 & $.000^{\text {a }}$ \\
\cline { 2 - 7 } & Residual & 118.520 & 18 & 6.584 & & \\
\hline
\end{tabular}




\begin{tabular}{c}
\hline Total $295.810 \quad 20$ \\
\hline a. Predictors: (Constant), Motivasi Kerja (X2), Pengembangan Karir (X1) \\
\hline b. Dependent Variable: Kepuasan Kerja (Y) \\
\hline
\end{tabular}

Cara pengambilan keputusan terhadap hipotesis dapat dilakukan dengan membandingkan nilai $\mathrm{F}$ hitung dengan $\mathrm{F}$ tabel pada taraf signifikansi penelitian yaitu 0,05 . Jika nilai $\mathrm{F}$ hitung < $\mathrm{F}$ tabel maka hal ini berarti pengaruh antara variabel bebas secara keseluruhan terhadap variabel terikat tidak signifikan secara statistik. Namun jika nilai $F$ hitung > F tabel maka hal ini berarti pengaruh antara variabel bebas secara keseluruhan terhadap variabel terikat signifikan secara statistik. Nilai $F$ tabel untuk jumlah responden 21 orang dan variabel sebanyak 3 pada taraf signifikansi 0,05 adalah 3,55.

Berdasarkan Tabel, nilai F hitung adalah 13,463. Karena nilai F hitung lebih besar dari $\mathrm{F}$ tabel, maka dapat disimpulkan bahwa variabel-variabel bebas secara simultan berpengaruh signifikan terhadap variabel terikat secara statistik.

\section{Analisis Koefisien Determinasi}

Tabel 6 Analisis Koefisien Determinasi

\begin{tabular}{lcccc}
\hline \multicolumn{4}{c}{ Model Summary } \\
\hline $\begin{array}{l}\text { Mode } \\
1\end{array}$ & $\mathrm{R}$ & R Square & $\begin{array}{c}\text { Adjusted R } \\
\text { Square }\end{array}$ & $\begin{array}{c}\text { Std. Error of the } \\
\text { Estimate }\end{array}$ \\
\hline 1 & $.774^{\mathrm{a}}$ & .599 & .555 & 2.56602 \\
\hline a. Predictors: (Constant), Motivasi Kerja (X2), Pengembangan Karir (X1) \\
\hline b. Dependent Variable: Kepuasan Kerja (Y) \\
\hline
\end{tabular}

Berdasarkan Tabel, nilai koefisien determinasi $R^{2}$ terletak pada kolom $R$-Square. Diketahui nilai koefisien determinasi sebesar $R^{2}=0,599$. Nilai tersebut berarti Pengembangan Karir dan Motivasi Kerja mempengaruhi secara simultan atau bersamasama terhadap variabel Kepuasan Kerja Karyawan sebesar 59,9\%, sisanya sebesar 40,1\% dipengaruhi oleh faktor-faktor lain.

\section{KESIMPULAN}

Kesimpulan yang dapat di Tarik dari penelitian ini ialah diketahui bahwa pengembangan karir memiliki pengaruh baik terhadap tingkat kepuasan kerja karyawan yang memang berbeda beda setiap individu.

\section{DAFTAR PUSTAKA}

Evan Nalendra (2008). Pengaruh Kompensasi Dan Motivasi Kerja Terhadap Kepuasan Kerja Karyawan Pada PT. Karya Sejati Vidyatama. Jurnal Jurusan Manajemen Fakultas Ekonomi Universitas Katolik Soegijapranata.

Handoko (2005). Manajemen Personalia dan Manajemen Sumber Daya Manusia. Bandung: Cita Pustaka Media Perintis

Husaini Usman (2009). Manajemen Teori, Praktik, Dan Riset Pendidikan. Edisi 3. Jakarta Timur : PT. Bumi Aksara

Kadarisman (2013). Manajemen Pengembangan Sumber Daya Manusia, Edisi 1. Jakarta : Rajawali Pers 
Lamsiska Rosalina (2016). Pengaruh Pengembangan Karir dan Motivasi Terhadap Kinerja Karyawan Pada Verena Multi Finance Tbk Cabang Pekanbaru. Pekanbaru. FISIP Universitas Riau

Malayu S.P. Hasibuan (2011). Manajemen Dasar, Pengertian, Dan Masalah. Edisi Revisi. Jakarta: PT. Bumi Aksara

Puji Isyanto (2013). Pengaruh Pengembangan Karir Terhadap Motivasi Karyawan Pada PT. Excel Utama Indonesia Karawang. Jurnal Jurusan Manajemen Vol. 10 No. 3

Raymond A. Noe (2011). Manajemen Sumber Daya Manusia Mencapai Keunggulan Bersaing. Cetakan Kedua. Jakarta : Selemba Empat 